\title{
Analysing Inflation: Monetary and Real Theories
}

\begin{abstract}
M. SHAUKAT ALI
The paper seeks to analyse the inflationary trends observed in Pakistan in the recent past by applying both the monetary and real theories. The former explains inflation in terms of changes in liquidity per unit of real output and velocity whereas the latter makes use of real variables, especially, the structure of economy.

Since the ratio between money spending (quantity of money times velocity) and real GDP defines general price level, monetary theory offers a natural tool for analysing inflation. Even factors like raising utility prices by the government or higher expected inflation add to inflation only when the additional demand for money generated by these factors is met with an accommodating increase in money supply (with stable velocity). During FY86 to 96 in Pakistan, money supply grew by 15.4 percent, GDP by 5.3 percent, and velocity by -0.24 percent. This yields an estimated inflation of 9.4 percent, very close to the actual one of 9.2 percent. Interestingly enough, more than half of the money expansion during the 90s emanated from credit for budgetary support, rendering the latter an active source of inflation.

Under the real theory, we focused on full-cost-pricing wherein the market value-added price is defined as a weighted sum of various primary costs, e.g., wages, profits, and net indirect taxes. To capture the impact of terms of trade, foreign trade flows were added. It has been estimated that the overall inflation of 9.4 percent during FY86-95 was contributed to the extent of 5.6 points by profits, 2.2 points by wages, 0.9 by net indirect taxes and 0.7 by terms of trade.

From policy perspective, monetary analysis has an edge over real analysis as controlling inflation through monetary management is relatively easier than through regulating various costs elements which go into the formation of price.
\end{abstract}

Broadly speaking, there are two theories of inflation: monetary theory and real theory. The monetary theory, in its present form, explains inflation in terms of changes in liquidity per unit of real output and velocity. The real theory tends to explain inflation in terms of real variables, especially, the structure of the economy.

Empirically, the analyses undertaken under real theory have taken several forms. The simplest form has been the decomposition of overall inflation into its components, i.e., quantifying contributions made to the overall inflation by various commodity groups, such as, food, clothing, housing, cleaning, etc. Another form has focused on decomposition of inflation by sources, i.e., quantifying the contributions made to the overall inflation by domestic wage and non-wage components and external (terms of trade) component. Yet another form is reflected in the Structural Model of inflation

M. Shaukat Ali is Chief, International Economics, The Planning Commission, Government of Pakistan, Islamabad. 
where inflation is attributed to differences in productivity growth of industrial and services sectors and differences in price and income elasticities of the two sectors. ${ }^{1}$

In the literature on the subject, some studies are also available where both the theories have been mixed with a view to have a better tracking of inflationary behaviour, though it lacks theoretical perfection. In such studies, policy inference from the estimated coefficients must be avoided as this may at times be quite misleading (see for example, Naqvi et al. PIDE Study (1994) wherein the money supply elasticity of price level was found to be as low as 0.11 , which neither stands to theory nor to empiricism).

The objective of the paper is to apply the two approaches separately to Pakistan's data and analyse the inflationary behaviour observed in the recent past.

\section{MONETARY APPROACH}

The monetary approach, based on the quantity theory of money, defines price level $(P)$ in terms of quantity of money premised on a very simple idea that total spending approximated by quantity of money in existence $(M)$ times its velocity $(V)$ must equal the value of output sold measured simply by the volume of output $(y)$ times average price level.

$$
\begin{array}{lllllll}
M V=P y & \ldots & \ldots & \ldots & \ldots & \ldots & \ldots
\end{array}
$$

This defines price level as:

$$
P=V \cdot(M / y)^{2} \quad \ldots \quad \ldots \quad \ldots \quad \ldots \quad \ldots \quad \ldots
$$

where $(M / y)$ is an index of money density representing money stock per unit of real output. The 'old' quantity theory within the overall framework of the Classical Economics of which it made an integral part, inferred two propositions from these equations:

(i) Causality: changes in $M$ lead to changes in $P$.

(ii) Proportionality: $P$ changes proportionately to $M$.

The inference was based on the three postulates of the Classical Economics, that is: (i) money is primarily a medium of exchange; (ii) $V$ is more or less stable because the

\footnotetext{
${ }^{1}$ An extended version of the Structural Model, commonly known as Scandinavian Model of Inflation, combines elements of structural explanation of inflation with a special transmission mechanism through which inflation from rest of the world is transmitted to a small open economy.

${ }^{2}$ This is famous Fisher equation of the quantity theory of money. An alternative equation is the one based on the Cambridge version which starts from the idea that people desire to hold a certain $(k)$ proportion of the their real income $(y)$ as real cash balances $(M / P)$ for transaction purposes:

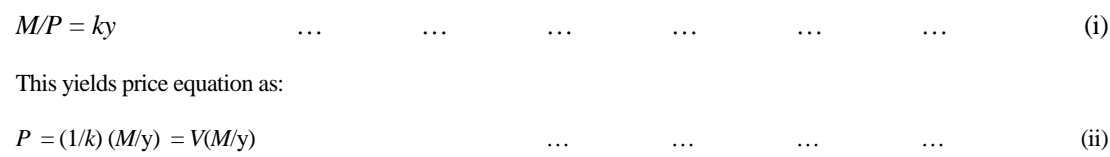


institutional factors which determine velocity seldom vary in short run; and (iii) labour market generally clears at full employment. Thus, in terms of growth rates (denoted by $\wedge$ ), Equation (2) takes a special form:

$$
\hat{P}=\hat{M} \quad \ldots \quad \ldots \quad \ldots \quad \ldots \quad \ldots \quad \ldots
$$

suggesting that growth in money supply is a unique sufficient condition for inflation.

In the post-world war era, the postulates about the constancy of output and velocity have been found less likely to hold empirically. Existence of unemployment and hence phenomenon of actual output falling below the potential one has turned out to be a norm rather than exception. Velocity was also found to be behaviourally related to certain factors which at times showed changing trends. Similarly, the speculative demand for money as pointed out by Keynes, tended to undermine the very hypothesis that money was primarily a medium of exchange.

These observations, however, do not negate the main message of the quantity theory. What they factually do, is that they undo the 'proportionality' relationship. Now, what becomes important is to look into correlation between the inflation rate on the one hand and the rate of growth of money stock net of real output growth and change in velocity, on the other hand. This is what the refined version of the quantity theory, as given by Friedman in his 'Restatement' of the Quantity Theory (1956), implies.

The basic idea of the monetary theory of inflation is, to borrow from Friedman (1968), that "inflation is always and everywhere a monetary phenomenon". It does not, however, mean that non-monetary variables do not play any role in the determination of inflation. In fact, what the theory assumes is that any change in domestic aggregate demand or aggregate supply or in external flows is reflected in changes in money density and hence affects inflation. Similarly, it is believed that any upward adjustment in utility prices by the government or higher expected inflation by general masses will add to inflation as the additional demand for money generated by these factors for financing transactions at higher prices is met either with an accommodating increase in money supply or through increase in velocity. If the accommodating increase is not forthcoming and velocity remains stable, only relative prices will change with no effect on inflation. Thus, while money expansion acts as an umbrella cause of inflation, in actual all the factors responsible for excessive money expansion can be held responsible for inflation. The resort to excessive bank borrowing by the government to finance budget deficit is one such typical example.

Empirically, the refined version of the quantity theory seems to explain variations in inflation rates both across countries and over time with a fair degree of accuracy. Schwartz (1973), by means of a sample of 40 countries and data for the period 1952-69, tested the hypothesis that the various rates of inflation in different countries can be explained by the respective rates of growth of money density and found a simple 
correlation coefficient as high as 0.94 . In a diagram with inflation rate plotted on vertical axis and growth rate of $M / y$ on horizontal axis, the observations were found to be distributed relatively narrowly around the $45^{\circ}$ line. Barro (1984) compiled crosscountry data for 83 countries on growth rates of money, price, and output in the postworld war II period which suggested that, on average (measured in terms of median), the growth of money supply per unit of output had been 6.1 percent and the growth in price level 6.2 percent. Barro also collected time series data for the United States for 120 years (from 1860 to 1980) which also showed a similar result; on the average, the inflation rate had been 2.1 percent per annum and the growth rate of money supply per unit of output 2.3 percent per annum.

\section{Application to Pakistan}

The refined version of Equation (2) provides a simple model which can be used to analyse inflation. In terms of growth rates, Equation (2) becomes:

$$
\hat{P}=\hat{V}+(M / \hat{y}) \quad \ldots \quad \ldots \quad \ldots \quad \ldots \quad \ldots
$$

Since $M$ is a stock variable while $Y$ a flow, to relate $M$ with $y$ in the density index, $M$ needs to be converted into some kind of flow variable $(M F)$ : either 12 months average; or average of the current and preceding year, like:

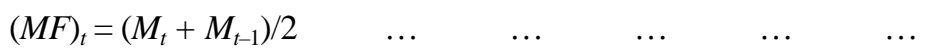

Finally, since Equation (5) runs in terms of overall GDP and total money supply, the price level $(P)$ explained by the model would be nearer to GDP Deflator (rather than Consumer Price Index, CPI).

The inflation estimated through Equations (4) and (5) and the actual inflation have been compared in Table 1 .

Table 1

Model Estimated vs Actual Inflation (GDP Deflator)

\begin{tabular}{cccc}
\hline Year & Actual & Estimated & Pure Noise \\
\hline $85-86$ & 3.3 & 3.6 & -0.3 \\
$86-87$ & 4.5 & 4.7 & -0.2 \\
$87-88$ & 9.6 & 9.4 & 0.2 \\
$88-89$ & 8.6 & 8.4 & 0.2 \\
$89-90$ & 6.5 & 6.4 & 0.1 \\
$90-91$ & 13.1 & 12.7 & 0.4 \\
$91-92$ & 10.1 & 10.7 & -0.6 \\
$92-93$ & 8.7 & 10.8 & -2.2 \\
$93-94$ & 12.9 & 12.9 & 0.0 \\
$94-95$ & 13.6 & 13.4 & 0.2 \\
$95-96$ & 10.0 & 10.0 & 0.0 \\
11 Years Avg. & 9.17 & 9.36 & -0.19 \\
\hline
\end{tabular}


In the 11 years, actual inflation, on avenge, amounted to 9.2 percent per annum. The estimated inflation works out to be 9.4 percent implying a very little unexplained residual. The estimated inflation of 9.4 percent was contributed to the extent of 9.8 percentage points by rise in money density index and -0.4 percentage points in velocity. The money density growth comprised growth of 15.2 percent in money supply in flow terms (16.1 percent at end period stock basis) ${ }^{3}$ and 5.3 percent in real GDP.

\section{REAL THEORY}

For real theory analysis of inflation, we have focused on decomposing inflation by sources. The methodology to this effect stems from the full-cost-pricing theory wherein the market value-added price is defined as a weighted sum of various primary costs, with weights reflecting the share in total cost. The costs cover wages, profits, and net indirect taxes. With a view to capture the impact of terms of trade, however, foreign trade flows can also be added to the analysis. Of course, in the latter case, the price level must be approximated by the economy's total domestic demand deflator rather than by the simple GDP deflator. A working equation for the desired decomposition has been derived as: ${ }^{4}$

${ }^{3}$ Looking at the contributions of various causative factors to this overall growth of money supply, it is interesting to note that during the six years of the 1990s, more than half of the money expansion emanated solely from credit to government for budgetary support purposes, rendering the latter a significant source of inflation.

${ }^{4}$ Following the OECD Survey of Austria (1994), a working equation has been derived by combining the two definitional equations of GDP deflator, one based on components and the other on sources. Let the symbols be defined first, as follows:

$$
\begin{array}{ll}
\text { Py } & \text { GDPmp deflator. } \\
Y & \text { GDPmp }
\end{array}
$$

TR Total resources (National Accounts (NA) basis).

E Exports g\&nfs (NA basis).

$M$ Imports g\&nfs (NA basis).

Pd Total domestic demand deflator.

$P e$ Export deflator.

Pm Import deflator.

$W$ Wages in nominal terms.

$R$ Profits in nominal terms.

NIT Net indirect taxes in nominal terms.

$n, r$ Subscript $n$ denotes nominal values, and $r$ denotes real values based on 1980-81 prices.

The component-based GDP deflator (Py) can be expressed as:

$P y=(Y n / Y r)$

$=(T R n+E n-M n) / Y r$

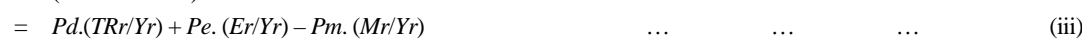

The source-based $P y$ can be written as:

$P y=(W+R+N I T) / Y r$

Combining (iii) and (iv) and solving for $P d$ in terms of growth rates, yields the working equation:

$$
\begin{aligned}
P \hat{d}= & (W / T R n) \cdot(W / Y \hat{r})+(R / T R n) \cdot(R / Y \hat{r}) \\
+ & (N I T / T R n) .(N I T / Y \hat{r})-(E n / T R n) .(P \hat{e}) \\
+ & (M n / T R n) .(P \hat{m})+e
\end{aligned}
$$

where $e$ may be attributed to the compositional change. 


$$
\begin{aligned}
& P \hat{d}=(W / T R n) .(W / Y \hat{r})+(R / T R n) .(R / Y \hat{r})+(N I T / T R n) .(N I T / Y \hat{r}) \\
& -(E n / T R n) .(P \hat{e})+(M n / T R n) .(P \hat{m})+e \quad \ldots \quad \ldots \quad \ldots
\end{aligned}
$$

Equation (6) explains inflation approximated by changes in total domestic demand deflator through changes in wage cost, profit cost, tax cost, and terms of trade, all duly weighted by their respective shares in total resources of the economy.

\section{Application to Pakistan}

Data except for wages and profits is available from the published sources, particularly Pakistan (1995). Wage series for 1983-84 to 1990-91 was taken from the Sub-committee Report on Income Distribution [PIDE (1992)]. Following the revision of pay scales in June 1991, an average increase of 18 percent in wages and salaries was allowed for 1991-92. The ratio of wage/GDP for 1991-92 was then extended for 199293 and 1993-94. In 1994-95, again an average increase of 25 percent was allowed in line with the revision of pay scales in May 1994. Profits were derived from GDP as residual. The results of Equation (6) are reported in Table 2.

The largest contribution came from profits, followed by wages, indirect taxes and terms of trade. The contribution of terms of trade combines -1.48 percentage points from exports and 2.15 percentage points from imports.

Table 2

Causative Factors of overall Inflation

(Total Domestic Demand Deflator)

\begin{tabular}{lrlllrl}
\hline & Overall & \multicolumn{5}{c}{ Percentage Point Contribution } \\
\cline { 3 - 7 } Year & Inflation & $\mathrm{W}$ & $\mathrm{R}$ & $\mathrm{NIT}$ & \multicolumn{1}{c}{ TOT } & \multicolumn{1}{c}{$\mathrm{e}$} \\
\hline $85-86$ & 3.60 & 2.4 & 0.99 & -0.25 & 0.40 & 0.06 \\
$86-87$ & 3.65 & 2.06 & 1.23 & 1.04 & -0.79 & 0.12 \\
$87-88$ & 10.50 & 1.61 & 5.32 & 2.16 & 1.71 & -0.30 \\
$88-89$ & 9.74 & 0.10 & 6.95 & 1.15 & 1.75 & -0.21 \\
$89-90$ & 6.95 & 1.68 & 3.69 & 0.65 & 0.95 & -0.02 \\
$90-91$ & 15.75 & 2.27 & 8.9 & 1.11 & 3.51 & -0.10 \\
$91-92$ & 8.65 & 2.21 & 6.43 & 1.09 & -1.62 & 0.52 \\
$92-93$ & 9.17 & 2.93 & 4.81 & 0.40 & 0.96 & 0.07 \\
$93-94$ & 12.48 & 2.14 & 9.71 & 0.86 & -0.017 & -0.22 \\
$94-95$ & 13.59 & 4.91 & 8.36 & 0.93 & -0.24 & -0.31 \\
10 Years Avg. & 9.41 & 2.23 & 5.64 & 0.91 & 0.67 & -.04 \\
\hline
\end{tabular}




\section{CONCLUSION}

Depending on the interest of the researcher, inflation can be analysed by either of the two approaches spelled out in the paper. From the policy point of view, however, monetary analysis has an edge as controlling inflation through monetary management is relatively easier and effective than through regulating various costs elements which go into the formation of price under real theory.

\section{REFERENCES}

Ali, M. Shaukat (1996) Causality Between Money Supply and Price Level: Evidence in Theory and Practice. The Kashmir Economic Review 45-56.

Barro, R. J. (1984) Macroeconomics. John Wiley \& Sons.

Friedman, M. (1956) The Quantity Theory of Money: A Restatement. In Studies in the Quantity Theory of Money. Chicago: The University of Chicago Press.

Friedman, M. (1968) Inflation: Causes and Consequences. In Dollars and Deficits. New Jersey: Prentice-Hall, Englewood Cliffs.

Naqvi, Syed Nawab Haider, Ashfaque H. Khan Ather Maqsood Ahmed and Rehana Siddiqui (1994) Inflation in Pakistan:Causes and Remedies. Islamabad: Pakistan Institute of Development Economics.

OECD (1994) Survey of Austria.

PIDE (1992) Committee on Economic and Social Well-being for the Eighth Five Year

Plan: Final Report of the Sub-committee on Personal, Functional and Regional Income Distribution, Islamabad.

Schwartz, Anna J. (1973) Secular Price Changes in Historical Perspective. Journal of Money, Credit and Banking Part II 5(1), February. 